\title{
Decreases in elemental carbon and fine particle mass in the United States
}

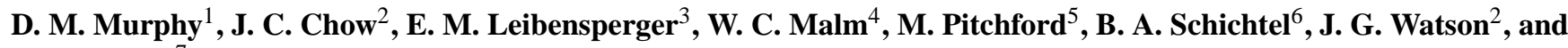 \\ W. H. White ${ }^{7}$ \\ ${ }^{1}$ Chemical Sciences Division, Earth System Research Laboratory, National Oceanic and Atmospheric Administration, \\ Boulder, CO 80305, USA \\ ${ }^{2}$ Division of Atmospheric Sciences, Desert Research Institute, Reno Nevada, 89512, USA \\ ${ }^{3}$ School of Engineering and Applied Sciences, Harvard University, Cambridge, MA, 02138, USA \\ ${ }^{4}$ Cooperative Institute for Research in the Atmosphere, Colorado State University, Fort Collins, CO 80523, USA \\ ${ }^{5}$ Air Resources Laboratory, National Oceanic and Atmospheric Administration, Las Vegas, NV 89119, USA \\ ${ }^{6}$ National Park Service, Colorado State University, Foothills Campus, Fort Collins, Colorado 80523, USA \\ ${ }^{7}$ Crocker Nuclear Laboratory, University of California Davis, Davis, CA 95616, USA
}

Received: 30 December 2010 - Published in Atmos. Chem. Phys. Discuss.: 20 January 2011

Revised: 4 May 2011 - Accepted: 13 May 2011 - Published: 19 May 2011

\begin{abstract}
Observations at national parks and other remote sites show that average elemental carbon and fine particle mass concentrations in the United States both decreased by over $25 \%$ between 1990 and 2004. Percentage decreases in elemental carbon were much larger in winter than in summer. These data suggest that emissions controls have been effective in reducing particulate concentrations not only in polluted areas but also across the United States. Despite the reduction in elemental carbon, the simultaneous decrease in non-absorbing particles implies that the overall radiative forcing from these changes was toward warming. The use of a 2005 instead of 1990 as a baseline for climate-relevant emissions from the United States would imply a significantly lower baseline for aerosol emissions. The use of older data will overestimate the possibility for future reductions in warming due to black carbon controls.
\end{abstract}

\section{Introduction}

Fine particles in the atmosphere, or aerosol, are important climate forcing agents. Non-absorbing particles cool the Earth whereas sufficiently light-absorbing particles warm the Earth. Controls on black carbon (BC) have been proposed as part of a strategy to reduce abrupt climate change (Molina et al., 2009). Trends in BC therefore have implications for

Correspondence to: D. M. Murphy

(daniel.m.murphy@noaa.gov) policy, showing both the effectiveness of past control strategies and the possibilities for future reductions. We use data from the Interagency Monitoring of Protected Visual Environments (IMPROVE) network of aerosol samplers (Malm et al., 1994, 2004) to examine trends in the United States between 1990 and 2004. These data indicate decreases in both fine particle mass and elemental carbon (EC) over wide areas of the United States, in places by more than $50 \%$. Trends in EC in the US at single sites and/or shorter periods (Junker et al., 2004; Husain et al., 2008; Kirchstetter et al., 2008) as well as trends in fine mass in Canada (Hidy et al., 2010) support these decreases.

As motivation for national trends, Fig. 1 shows EC and $\mathrm{BC}$ measurements from northern California, chosen because independent data sets are available at Trinidad Head (Fiebig and Ogren, 2006) and the San Francisco Bay area (Kirchstetter et al., 2008). The trend in EC measurements at Redwood National Park is similar to that for the San Francisco Bay area except that absolute concentrations are a factor of 10 lower at Redwood National Park. A site at Point Reyes (not shown) shows a similar time series with absolute concentrations intermediate between San Francisco and Redwood NP. Aerosol light absorption, measured using a Particle Soot Absorption Photometer, also decreased at the NOAA monitoring site at Trinidad Head, California.

Despite a lack of strong local sources, concentrations at the Northern California sites respond primarily to US emissions. Even a coastal site such as Trinidad Head has significant contributions from California sources during offshore flow and periods of recirculation (Goldstein et al., 2004).

Published by Copernicus Publications on behalf of the European Geosciences Union. 


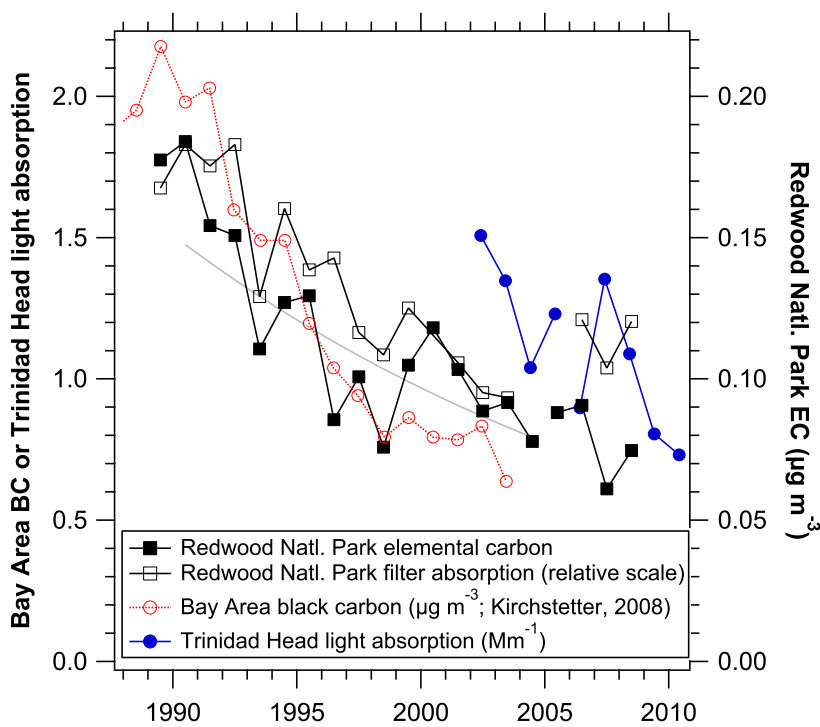

Fig. 1. Elemental carbon (EC) and light absorption trends for sites in northern California. The thin gray line is the fit for Redwood National Park (to the solid black squares). Redwood National Park data in 2004 and 2005 are not connected because of the change in instrumentation at the start of 2005. There was also an instrumentation change at Trinidad Head in late 2005.

Without sorting by a tracer or wind speed and direction, 24-hour samples, like IMPROVE, will sample significant amounts of local pollution from land breezes at these sites (Parrish et al., 2009).

\section{Sampling methods}

The IMPROVE network uses 24-hour filters that are collected every third day and analyzed at a central laboratory. Strengths of the IMPROVE data are the length of the record, the number of sites, and consistent techniques. All IMPROVE elemental and organic carbon analyses on quartz-fiber filters are performed at the same laboratory with the same protocols, the same suite of thermal/optical instruments, and consistent calibrations and quality assurance (Chow et al., 1993). The thermal/optical instruments were replaced in January 2005 so we focus on prior trends without the complication of this analytical change, which was flagged at: http://vista.cira.colostate.edu/improve/Data/ QA_QC/Advisory/da0016/da0016_TOR2005.pdf. The IMPROVE network uses a parallel module with a Teflonmembrane filter to measure the filter blackness and fine particle mass $\left(\mathrm{PM}_{2.5}\right.$; particles with aerodynamic diameters less than $2.5 \mu \mathrm{m})$. Except as noted, the IMPROVE sites are located in national parks, monuments, or similar areas and represent regional background conditions. The IMPROVE sampling protocol is described in de- tail at: http://vista.cira.colostate.edu/improve/Publications/ SOPs/UCDavis_SOPs/IMPROVE_SOPs.htm.

It is customary to distinguish between $\mathrm{BC}$ and $\mathrm{EC}$ even though they are closely related in the atmosphere. $\mathrm{BC}$ is derived from light absorption measurements, often using the attenuation of light reflected from or transmitted through a filter. EC is determined by physical analyses such as heating of the sample in oxidizing and non-oxidizing atmospheres, sometimes with an optical correction for charring of some organic carbon to EC during analysis. "Soot" is a specific form of elemental carbon produced by combustion. The quantitative relationship between $\mathrm{BC}$ and $\mathrm{EC}$ depends on the size of the particles, their morphology, and coating by nonabsorbing species (Watson et al., 2005; Bond and Bergstrom, 2006). There are large differences between $B C$ or EC measured by different methods (Watson et al., 2005).

\section{Trend analysis methods}

Trends were computed starting in 1990 because there were insufficient sites in earlier years. The thermal/optical carbon analyzers were changed at the end of 2004 and it will require additional work to understand a trend computed across a change in instrumentation. Preparatory testing (Chow et al., 2007) showed that organic and elemental carbon values would remain consistent. Average EC during 2004 was lower at most sites than either the 2003 and 2005 annual averages, which may have been caused by instrument deterioration before replacement. As a result, we have chosen to end the trend computations in early 2004. An integral number of years (1 March 1990 to 29 February 2004) was chosen to minimize dependence of the trends on the seasonal cycle. The sampling frequency was changed in 2000 from Wednesday and Saturday to every third day based on the US EPA calendar for air pollutant sampling. This should have little effect on trends because Wednesday and Saturday are almost precisely at the mean of the weekly cycle in EC (Murphy et al., 2008).

For each IMPROVE site, individual samples were averaged to quarterly values (e.g. December through February). At least 10 valid samples were required in each quarter or else the entire quarter was treated as a missing value. Elemental carbon (EC) values were capped at $5 \mu \mathrm{g} \mathrm{m}^{-3}$ to minimize the influence of a few of the most intense smoke plumes. This criterion affected less than $0.03 \%$ of the data. For the trends from 1 March 1990 through 29 February 2004, sites were chosen that were operational before January 1995 and had at least 35 quarterly values (of 56 possible). Most missing quarterly values were because a given site did not become operational until after March 1990. Fifty sites had sufficient data to compute trends. A list of these sites is given in supplemental material along with their quarterly averaged data. 
Trends were computed with simultaneous removal of the seasonal cycle. Removing the seasonal cycle is necessary because the seasonal cycle can bias the trends at those sites where the data start and stop in different seasons. Trends of annual averages were computed both for the linear model $A_{0} t+A_{1} \delta_{\mathrm{DJF}}+$ $A_{2} \delta_{\mathrm{MAM}}+A_{3} \delta_{\mathrm{JJA}}+A_{4} \delta_{\mathrm{SON}}+\varepsilon$ and the exponential model $\left(A_{1} \delta_{\mathrm{DJF}}+A_{2} \delta_{\mathrm{MAM}}+A_{3} \delta_{\mathrm{JJA}}+A_{4} \delta_{\mathrm{SON}}\right) \exp \left(A_{0} t\right)+\varepsilon$, where $A_{n}$ are fitted coefficients and $\delta_{\mathrm{DJF}}$ is 1 for data in December to February and 0 otherwise, etc. These two models have the same number of fit parameters and gave extremely similar trends. The exponential model is used in the figures because it had much smaller residuals at a few sites, generally those with the largest trends. There were no sites where it performed significantly worse than the linear model. Separate trends for each season naturally do not require removing the seasonal cycle.

The national average trends shown in the figures were computed from the percentage trends at various sites weighted by the absolute concentration at each site. If all sites had complete data records this would be to first order the same as the trend in the national average concentration. The extra step of computing separate trends for each site was necessary to minimize the impact of relatively clean or dirty sites entering the network in different years.

Trends in filter absorption (IMPROVE fabs) or "blackness" of the Teflon filters were computed after subtracting time-dependent zero offsets. These offsets are due to a 1994 change in the optical measurement as well as variations between different batches of filters. The correction is based on using the cleanest ambient filters as field blanks. In practice there are only a few very clean ambient filters and it is better to extrapolate back to zero concentration after excluding the dirtiest filters to avoid non-linear absorption. The offsets were computed 8 times per year from a multiple regression of filter absorption against EC and iron as a surrogate for light-absorbing mineral dust. These regressions used filters from the entire IMPROVE network, not just the sites that met our criteria for long-term trends. Similar offsets can be derived for a variety of techniques for estimating the field blank. The offset corrections reduce the computed trends in filter blackness over this period. No adjustment is made for the removal, in different years at different sites, of masks formerly used to reduce the effective collection area of the Teflon filters. Adjusting for the effects of unmasking would increase computed trends in filter blackness, as described at: http://vista.cira.colostate.edu/improve/ Data/QA_QC/Advisory/da0028/da0028_DA_mask_Fabs.pdf.

\section{Trend results}

Figure 2 shows the percentage trends in $\mathrm{EC}$ and $\mathrm{PM}_{2.5}$ mass for the 50 IMPROVE sites with sufficient data to compute a trend before 2005. There are decreases across the continental
US and at Denali National Park in Alaska. Only a handful of sites exhibit increases. We do not investigate the causes of the increases at individual sites. Some of the increases may be due to wildfire influence, as discussed in Sect. 5.1.

Figures 3 and 4 show the trends by season in EC and $\mathrm{PM}_{2.5}$ mass. The most important feature evident by season is the increase in $\mathrm{EC}$ and to a lesser extent $\mathrm{PM}_{2.5}$ in summer in the mountain west. Some individual sites are noisy for single seasons.

Figure 5 shows national average trends by season. The largest seasonal difference is that decreases in EC were larger in winter than summer. Trends in filter blackness (not shown), measured independently on different filters in the same samplers, showed the same pattern as EC. For example, the average 14-year trend in ECconcentrations was $-49 \%$ for December through February and $-15 \%$ for June through August (Fig. 5). The corresponding average changes in filter light absorption were about $-53 \%$ and $-27 \%$. Washington DC, the only urban site with a long enough data record, was excluded from Fig. 5 because it is clearly different than the background stations. Most obviously, the average EC value was larger. Including Washington DC would have slightly increased the magnitude of the national average trends for EC and $\mathrm{PM}_{2.5}$ mass.

Some IMPROVE sites have nephelometers or transmissometers in addition to filter samplers. The limited data show decreases in light scattering or extinction at most sites, as expected from the decreases in fine particle mass. However, the fine particle mass is a more reliable long-term measurement (http: //vista.cira.colostate.edu/improve/Publications/GrayLit/ TransDataUseWarning/TransDataUseWarning.htm).

\section{Discussion}

\subsection{Emission history}

The decreasing concentrations are almost certainly due to decreases in emissions from the United States. There is no reason to believe that removal processes changed by so much over this period. Long-range transport from Asian sources would cause an increase, not a decrease, during the period 1990-2005 (Bond et al., 2004). The importance of United States emissions is supported by consistently negative trends at eastern sites least susceptible to transport from outside the US (Fig. 2). From 1990 to 2004, EC decreased by almost $50 \%$ for the entire winter and spring (December through May) period (Figs. 3, 5). This would reduce the melting of snow cover induced by deposition of BC. Indeed, when trajectories came from North America, BC concentrations in the Arctic decreased significantly between 1990 and 1998 (Fig. 9b in Sharma et al., 2004).

Major sources of elemental carbon in the United States are internal combustion engines (especially diesels), wild and 

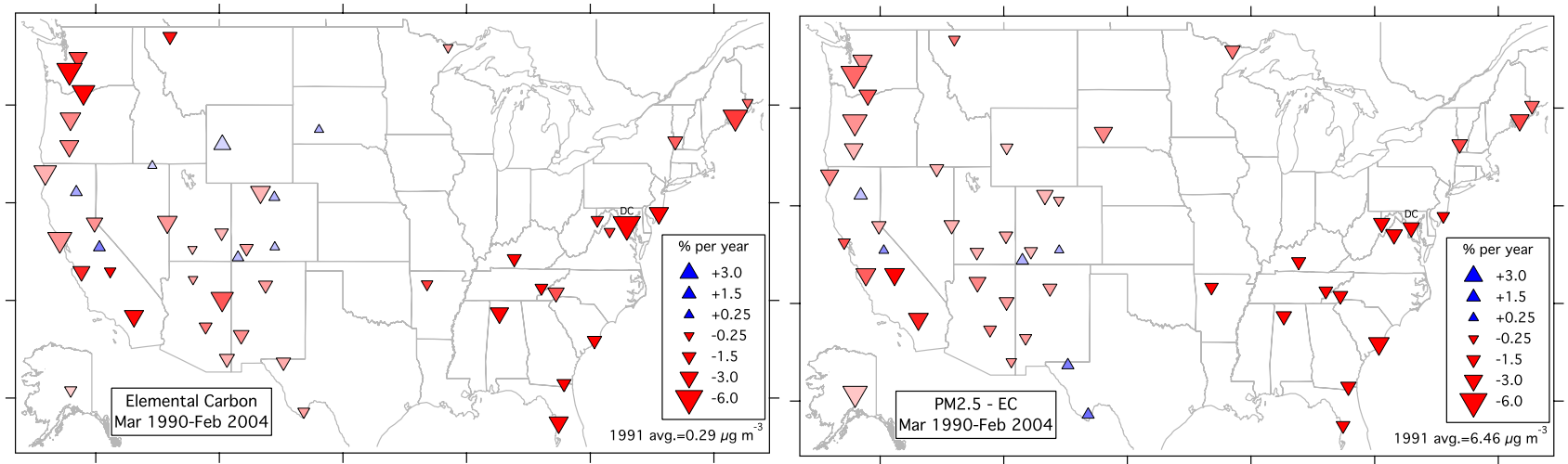

Fig. 2. Trends in EC and $\mathrm{PM}_{2.5}$ (fine particle) mass other than EC at all IMPROVE network stations with sufficient data between 1 March 1990, and 29 February 2004. Marker size indicates the magnitude of the trend. Triangle direction and blue or red color corresponds to the sign of the trend. Color saturation is proportional to the average concentration in 1991 with full saturation at twice the national median. The only urban site in Washington DC is marked. Averages in the bottom right corner exclude Washington DC.
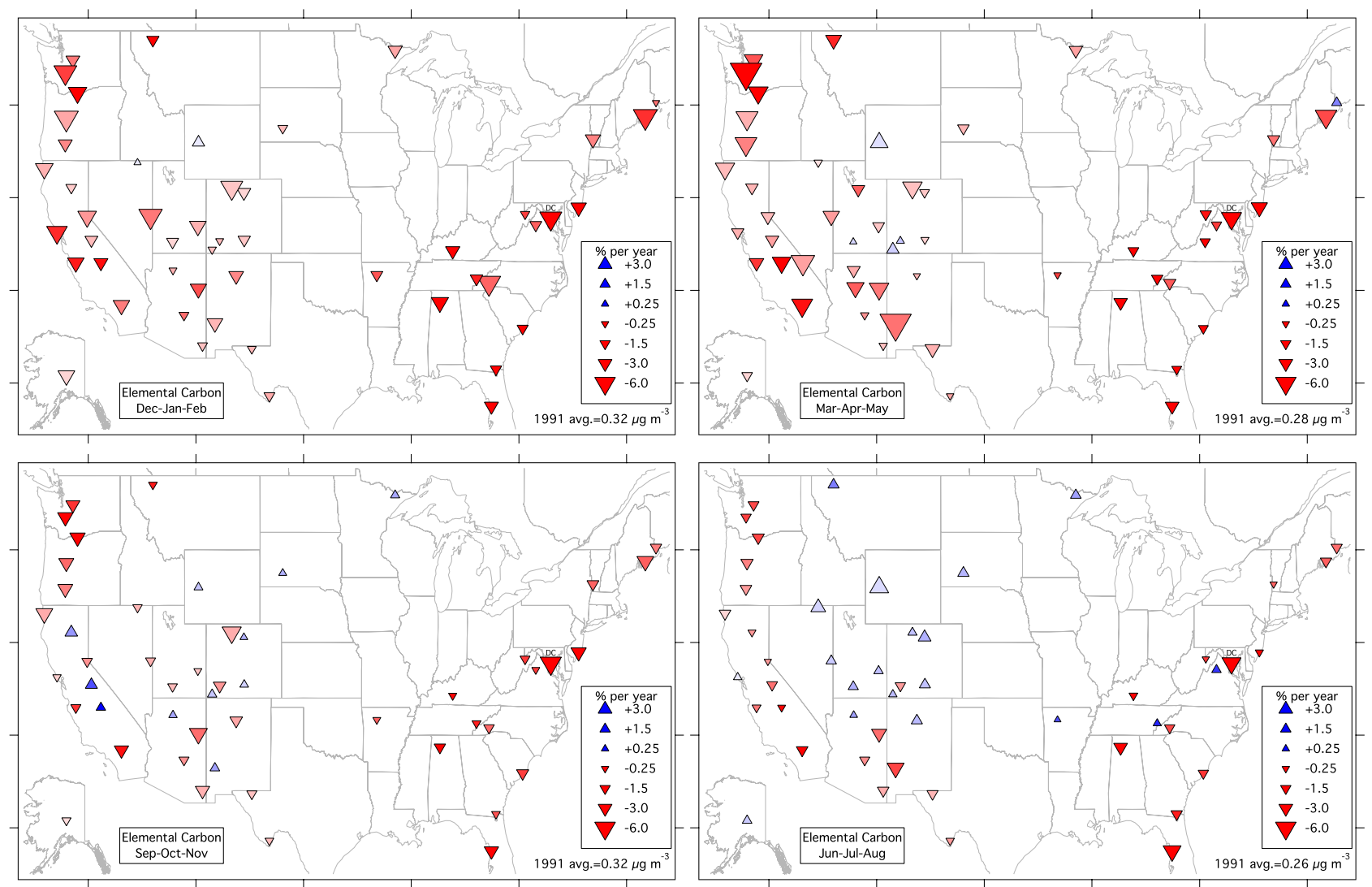

Fig. 3. Quarterly exponential trends in elemental carbon at IMPROVE network sites. As in Fig. 2, trends are for all stations with sufficient data between 1 March 1990, and 29 February 2004. Marker size indicates the magnitude of the trend. Triangle direction and blue or red color corresponds to the sign of the trend. Color saturation is proportional to the average concentration in 1991 with full saturation at twice the national median for each quarter. The only urban site in Washington DC is marked. Averages in the bottom right corners exclude Washington DC.

controlled burning of vegetation, and in places, wood stoves and other biofuels (Bond et al., 2004). Summer increases in EC were evident in the mountain western US (Fig. 3).
This is consistent with large decreases in controlled anthropogenic sources coupled with an increase in summer wildfires (Fig. 6). 

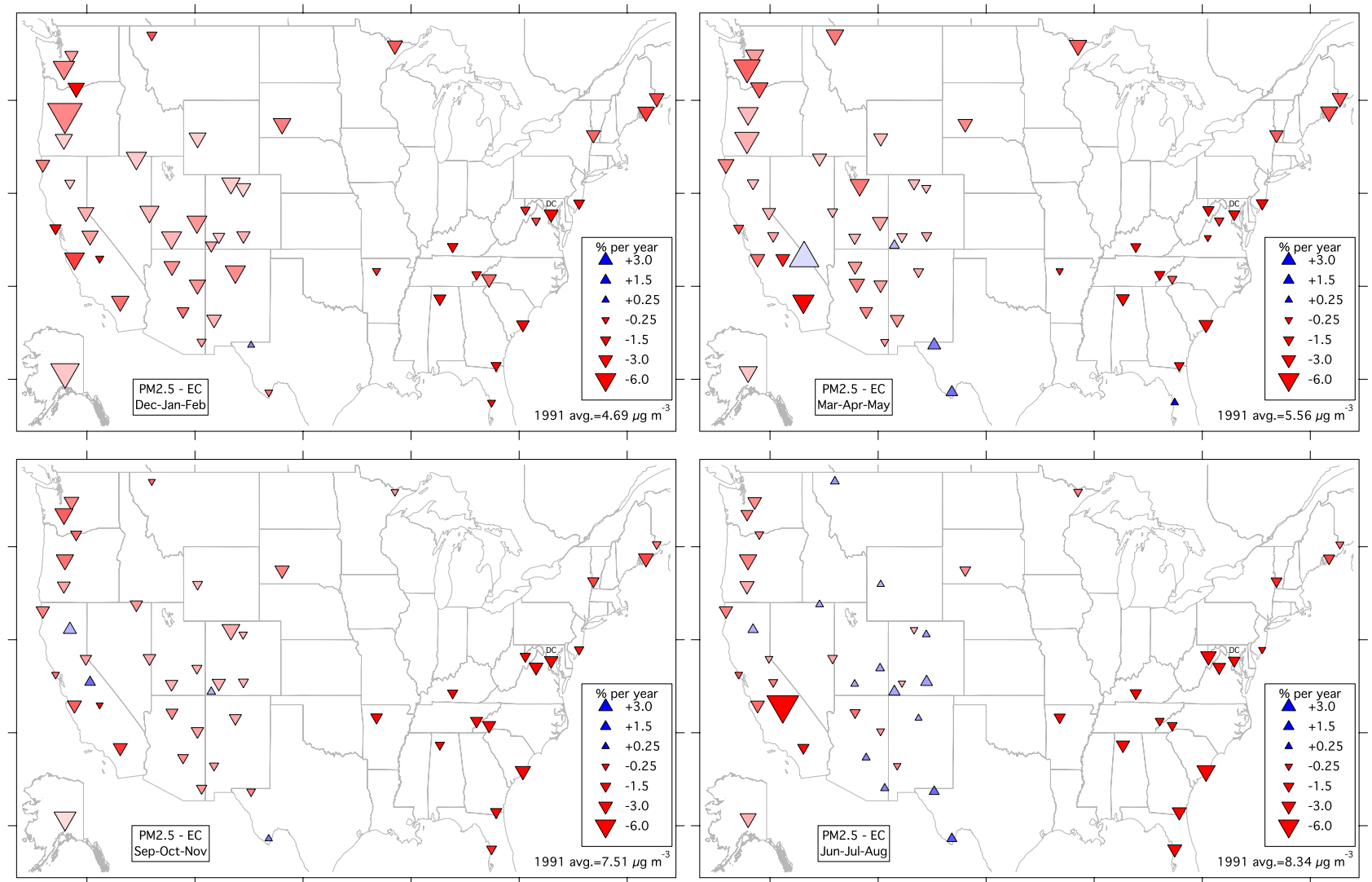

Fig. 4. Quarterly trends in fine mass other than elemental carbon at IMPROVE network sites. Symbols are as in Figs. 2 and 3.

A general smoke standard for heavy-duty highway diesel vehicles was introduced in 1970. Particulate standards for diesels (Yanowitz et al., 2000; Lloyd et al., 2001) were introduced at $0.6 \mathrm{~g} / \mathrm{bhp}-\mathrm{hr}$ in 1988 and reduced to 0.25 in 1991 , 0.1 in 1994 , and 0.01 in 2007. Due to the slow turnover of the truck fleet, a continuing response would be expected from earlier regulations. On-road measurements show that the emission factor of particulate matter from diesel trucks fell by 4 to $5 \%$ per year between 1988 and 1996 (Yanowitz et al., 2000) and 1997 to 2006 (Ban-Weiss et al., 2008). Total emissions would have decreased less because emissions factors are multiplied by increasing fuel use (Dallmann and Harley, 2010). A strong Sunday-Monday minimum in EC implies that even the remote IMPROVE sites are significantly affected by diesel trucks and off-road equipment which are used less on Saturdays and Sundays (Murphy et al., 2008).

Particulate emission standards for wood stoves were introduced in 1988 (US EPA). As with diesel trucks, slow turnover would mean that these standards had a gradually increasing impact. The large decreases in EC in winter are consistent with a contribution from controls on wood stoves.

Starting in $1999, \mathrm{PM}_{2.5}$ concentrations have been monitored at a large network of sites by the US Environmental Protection Agency. Most of these sites are urban, so they represent different conditions than the IMPROVE sites used here. Analyzing these sites is beyond the scope of this paper. Nevertheless, recent decreases in $\mathrm{PM}_{2.5}$ concentrations at the EPA sites (http://www.epa.gov/airtrends/pm.html) are broadly consistent with the decreasing trends in $\mathrm{PM}_{2.5}$ at the IMPROVE sites.

\subsection{Correlations with other species}

EC accounts for about $5 \%$ of the fine particle $\mathrm{PM}_{2.5}$ mass at non-urban IMPROVE sites. Therefore, the observed trend in mass must be caused by more abundant species. Most of the decrease in $\mathrm{PM}_{2.5}$ mass was due to organic carbon and sulfate. Silicon and other mineral dust elements in $\mathrm{PM}_{2.5}$ increased from 1990 to 2004.

Trends in EC at individual sites were uncorrelated with trends in sulfate. In contrast, trends in EC and organic carbon were correlated (Fig. 7). The total carbon, which can be measured more reliably than either component (Cavalli et al., 2010), decreased. Decreasing emissions from wood stoves would reduce both elemental and organic carbon. Decreases in EC in Japan were also correlated with organic carbon (Minoura et al., 2006). Recent work suggests that, because of semi-volatile compounds, the formation of 


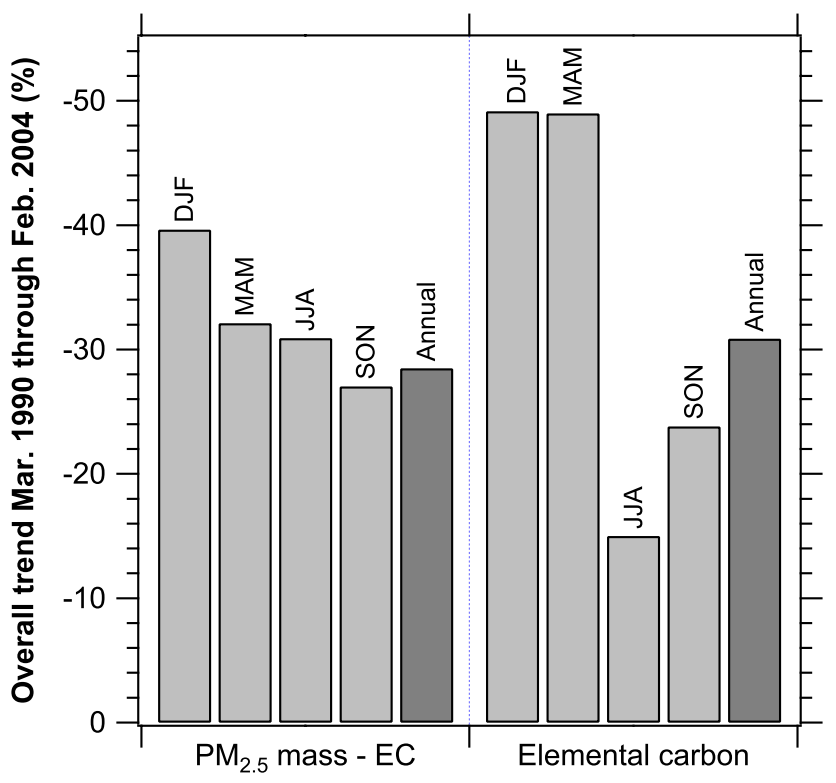

Fig. 5. Seasonal average national trends for the 14-year period 1 March 1990 to 29 February 2004 for elemental carbon and the balance of fine particle mass. (DJF: December, January, and February; MAM: March, April, and May; JJA: June, July, and August; and SON: September, October, and November).

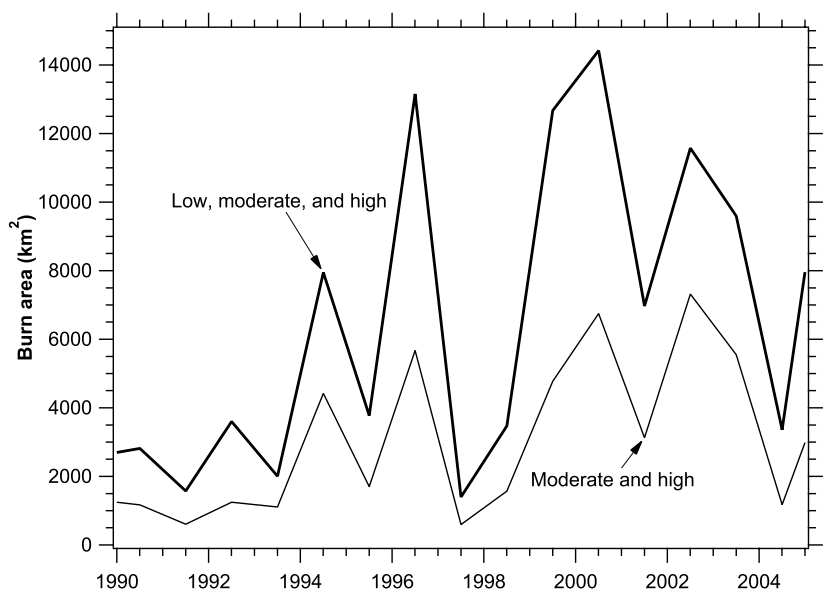

Fig. 6. Annual burn areas for the continental United States by fire severity from the Monitoring Trends in Burn Severity project of the US Forest Service and US Geological Survey (http://mtbs.gov/data/ search.html).

secondary organic aerosol from diesel engines is much larger than previously thought (Weitkamp et al., 2007; Miracolo et al., 2010). If so, reductions in diesel emissions may be responsible for much of the trend in both EC and organic carbon mass.

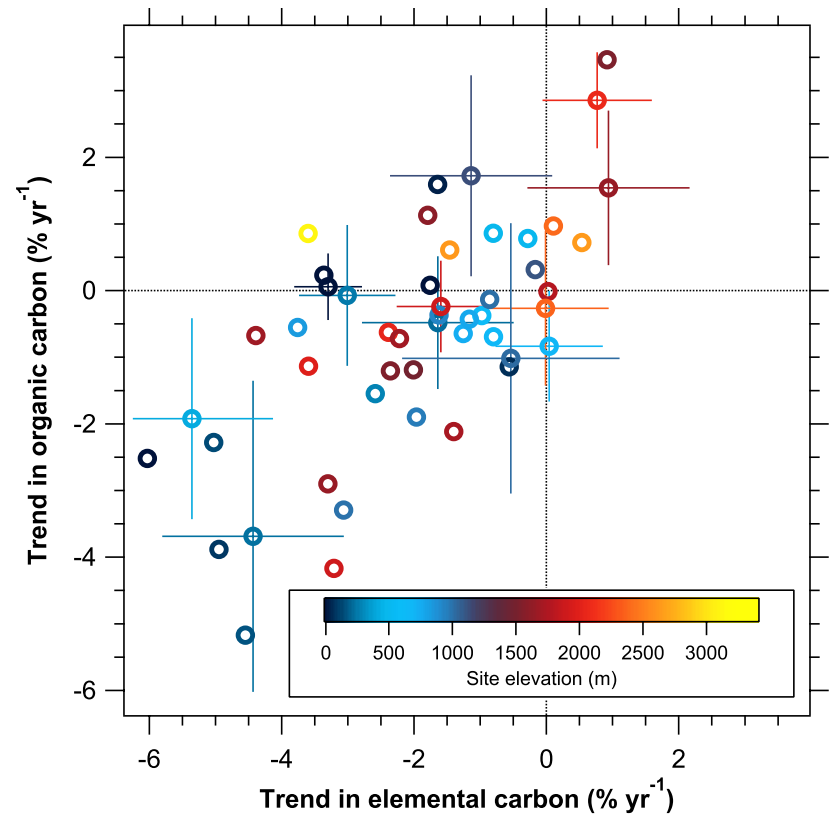

Fig. 7. The relationship between trends in organic and elemental carbon for each IMPROVE site shown in Fig. 2. Uncertainties $(1 \sigma)$ for the trend fits are shown for a subset of the sites.

\subsection{Implications for radiative forcing}

Black particles produce warming and non-absorbing particles cooling. Radiative forcing was calculated using the GISS GCM3 general circulation model with aerosol fields provided by the GEOS-Chem chemical transport model (Rind et al., 2007; Chen et al., 2010). These calculations are conducted with parallel radiative calculations within the model. The model is run with specified sea surface temperatures and sea ice coverage. Additional information about the GEOS-Chem and radiative forcing simulations can be found in Leibensperger et al. (2011). Radiative forcings for BC and the sum of sulfate, organics, and nitrate were computed for each month and aggregated to season and annual quantities. The $\mathrm{BC}$ forcing for each season was multiplied by the observed percentage trend in EC for that season, with a similar calculation for non-absorbing particles. The annual average change in forcing was computed from these seasonal changes.

Applying the observed percentage trends in concentration to US emissions in this pair of models, the decreases shown in Fig. 5 would produce a direct radiative forcing of $-0.09 \mathrm{~W} \mathrm{~m}^{-2}$ because of decreased black carbon and $0.39 \mathrm{~W} \mathrm{~m}^{-2}$ because of decreased non-absorbing particles, for a net of $0.3 \mathrm{~W} \mathrm{~m}^{-2}$ over the contiguous US. The net global forcing was calculated as $0.014 \mathrm{~W} \mathrm{~m}^{-2}$. GEOS-Chem underestimates absolute $\mathrm{BC}$ concentrations over the US but positive net forcing from the observed trends still holds if modeled $\mathrm{BC}$ over the US is doubled. The radiative forcings calculated here with the GISS GCM3 model do not include 
aerosol indirect effects on clouds or the radiative forcing from reduced albedo of snow following deposition of black carbon (Flanner et al., 2007, 2009). These omissions likely do not change the qualitative conclusion that the net change in aerosol forcing has been towards warming.

There are several implications to these trends. Emissions standards and restrictions implemented during the 1990s on diesel engines and residential wood-burning stoves have apparently had a significant effect on BC concentrations across the United States. Further reductions can be expected from the stricter diesel standards implemented in 2007 and the complementary low-sulfur fuel introduced nationally in 2006. It is important to use up-to-date emissions inventories to evaluate both health effects and radiative forcing. In Copenhagen, the United States proposed reductions in climate-relevant emissions compared to emissions in 2005 (http://www.state.gov/g/oes/rls/remarks/2009/ 121010.htm), whereas the Kyoto Protocol specified a 1990 baseline. Proposed US legislation on greenhouse gases has variously used 1990 or 2005 as baselines (Energy Information Administration, 2009; Pew Center, 2008). For carbon dioxide, 2005 provides a higher baseline than 1990. This work shows that black carbon has the opposite behavior: using 2005 as a reference year would mean a significantly lower baseline for US BC emissions than a 1990 baseline. Decreased concentrations imply that the room for reducing warming by controlling $\mathrm{BC}$ may be less than expected if older inventories are used.

\section{Supplementary material related to this article is available online at: http://www.atmos-chem-phys.net/11/4679/2011/ acp-11-4679-2011-supplement.zip.}

Acknowledgements. The authors acknowledge the federal and state sponsors of the IMPROVE network that make possible the generation and public availability of the data upon which this work depends. The IMPROVE program and steering committee are described at: http://vista.cira.colostate.edu/improve/. D. M. M. was supported by NOAA climate change funding. E. M. L. was supported by an EPA Science to Achieve Results (STAR) Graduate Fellowship. W. H. W. was supported by National Park Service contract C2350-06-4026. We thank John Ogren and Betsy Andrews of NOAA ESRL Global Monitoring Division for reprocessing their Trinidad Head data. The views presented herein are those of the authors and should not be interpreted as necessarily representing the policies of the agencies.

Edited by: T. Kirchstetter

\section{References}

Ban-Weiss, G. A., McLaughlin, J. P., Harley, R. A., Lunden, M. M., Kirchstetter, T. M., Kean, A. J., Strawa, A. W., Stevenson, E. D., and Kendall, G. R.: Long-term changes in emissions of nitrogen oxides and particulate matter from on-road gasoline and diesel vehicles, Atmos. Environ., 42, 220-232, 2008.

Bond, T. and Bergstrom, T.: Light absorption by carbonaceous particles: An investigative review, Aerosol Sci. Technol., 40, 27-67, 2006.

Bond, T. C., Streets, D. G., Yarber, K. F., Nelson, S. M., Woo, J.H., and Klimont, Z.: A technology-based global inventory of black and organic carbon emissions from combustion, J. Geophys. Res., 109, D14203, doi:10.1029/2003JD003697, 2004.

Cavalli, F., Viana, M., Yttri, K. E., Genberg, J., and Putaud, J.P.: Toward a standardised thermal-optical protocol for measuring atmospheric organic and elemental carbon: the EUSAAR protocol, Atmos. Meas. Tech., 3, 79-89, doi:10.5194/amt-3-79-2010, 2010.

Chen, W.-T., Nenes, A., Liao, H., Adams, P. J., Li, J.-L. F., and Seinfeld, J. H.: Global climate response to anthropogenic aerosol indirect effects: Present day and year 2100, J. Geophys. Res., 115, D12207, doi:10.1029/2005JD006545, 2010.

Chow, J. C., Watson, J. G., Pritchett, L. C., Pierson, W. R., Frazier, C. A., and Purcell, R. G.: The DRI thermal/optical reflectance carbon analysis system: Description, evaluation and applications in US air quality studies, Atmos. Environ., 27A, 1185-1201, 1993.

Chow, J. C., Watson, J. G., Chen, L.-W. A., Chang, M. C. O., Robinson, N. F., Trimble, D., and Kohl, S. D.: The IMPROVE-A temperature protocol for thermal/optical carbon analysis: Maintaining consistency with a long-term database, J. Air Waste Manage., 57, 1014-1023, 2007.

Dallmann, T. R. and Harley, R. A.: Evaluation of mobile source emission trends in the United States, J. Geophys. Res., 115, D14305, doi:10.1029/2010JD013862, 2010.

Energy Information Administration, US Department of Energy, "Energy Market and Economic Impacts of H. R. 2454, the American Clean Energy and Security Act of 2009", SR/OIAF/200905, 2009.

Fiebig, M. and Ogren, J. A.: Retrieval and climatology of the aerosol asymmetry parameter in the NOAA aerosol monitoring network, J. Geophys. Res., 111, D21204, doi:10.1029/2005JD006545, 2006.

Flanner, M. G., Zender, C. S., Randerson, J. T., and Rasch, P. J.: Present-day climate forcing and response from black carbon in snow, J. Geophys. Res., 112, D11202, doi:10.1029/2006JD008003, 2007.

Flanner, M. G., Zender, C. S., Hess, P. G., Mahowald, N. M., Painter, T. H., Ramanathan, V., and Rasch, P. J.: Springtime warming and reduced snow cover from carbonaceous particles, Atmos. Chem. Phys., 9, 2481-2497, doi:10.5194/acp-9-24812009, 2009.

Goldstein, A. H., Millet, D. B., McKay, M., Jaegle, L., Horowitz, L., Cooper, O., Hudman, R., Jacob, D. J., Oltmans, S., and Clarke, A.: Impact of Asian emissions on observations at Trinidad Head, California, during ITCT 2K2, J. Geophys. Res., 109, D23S17, doi:10.1029/2003JD004406, 2004.

Hidy, G. M. and Pennell, W. T.: Multipollutant air quality management, J. Air Waste Manage., 60, 645-674, 2010. 
Husain, L., Khan, A. J., Ahmed, T., Swami, K., Bari, A., and Webber, J. S.: Trends in atmospheric elemental carbon concentrations from 1835 to 2005, J. Geophys. Res., 113, D13102, doi:10.1029/2007JD009398, 2008.

Junker, C., Sheahan, J. N., Jennings, S. G., O’Brien, P., Hinds, B. D., Martinez-Twary, E., Hansen, A. D. A., White, C., Garvery, D. M., and Pinnick, R. G.: Measurement and analysis of aerosol and black carbon in the southwestern United States and Panama and their dependence on air mass origin, J. Geophys. Res., 103, D13201, , 2004.

Kirchstetter, T. A., Aguiar, J., Tonse, S., Fairley, D., and Novakov, T., Black carbon concentrations and diesel vehicle emission factors derived from coefficient of haze measurements in California: 1967-2003, Atmos. Environ., 42, 480-491, 2008.

Leibensperger, E. M., Mickley, L. J., Jacob, D. J., Chen, W.-T., Seinfeld, J. H., Nenes, A., Adams, P. J., D. G., Streets, Kumar, N., and Rind, D.: Climate effects of US aerosols over 1950-2050 - Part 1: Aerosol trends and radiative forcing, Atmos. Chem. Phys. Discuss., submitted, 2011.

Lloyd, A. C. and Cackette, T. A.: Diesel engines: Environmental impact and control, J. Air Waste Manage., 51, 809-847, 2001.

Malm, W. C., Sisler, J. F., Juggman, D., Eldred, R. A., and Cahill, T. A.: Spatial and seasonal trends in particle concentration and optical extinction in the United States, J. Geophys. Res., 99, 13471370, 1994.

Malm, W. C., Schichtel, B. A., Pitchford, M. L., Ashbough, L. L., and Eldred, R. A.: Spatial and monthly trends in speciated fine particle concentration in the United States, J. Geophys. Res., 109, D03306, doi:10.1029/2003JD003739, 2004.

Minoura, J., Takahashi, K., Chow, J. C., and Watson, J. G.: Multiyear trend in fine and coarse particle mass, carbon, and ions in downtown Tokyo, Japan, Atmos. Environ., 40, 2478-2487, 2006.

Miracolo, M., Presto, A. A., Lambe A. T., Hennigan, C. J., Donahue, N. M., Kroll, J. H., Worsnop, D. R., and Robinson, A. L.: Photo-oxidation of low-volatility organics found in motor vehicle emissions: Production and chemical evolution of organic aerosol mass, Environ. Sci. Technol., 44, 2029-2034, 2010.
Molina, M., Zaelkeb, D., Sarma, K. M., Andersen, S. O., Ramanathan, V., and Kaniaruf, D.: Reducing abrupt climate change risk using the Montreal Protocol and other regulatory actions to complement cuts in $\mathrm{CO}_{2}$ emissions, P. Natl. Acad. Sci. USA, 106, 20616-20621, 2009.

Murphy, D. M., Capps, S. L., Daniel, J. S., Frost, G. J., and White, W. H.: Weekly patterns of aerosol in the United States, Atmos. Chem. Phys., 8, 2729-2739, doi:10.5194/acp-8-2729-2008, 2008.

Parrish, D. D., Millet, D. B., and Goldstein, A. H.: Increasing ozone in marine boundary layer inflow at the west coasts of North America and Europe, Atmos. Chem. Phys., 9, 1303-1323, doi:10.5194/acp-9-1303-2009, 2009.

Pew Center on Global Climate Change: "Economy-wide Capand-Trade Proposals in the 110th Congress", available: www. pewclimate.org/docUploads/Chart-and-Graph-120108.pdf (last access: April 2011), 2008.

Rind, D., Lerner, J., Jonas, J., and McLinden, C.: Effects of resolution and model physics on tracer transports in the NASA Goddard Institute for Space Studies general circulation models, J. Geophys. Res., 112(19), D09315, doi:10.1029/2006JD007476, 2007.

Sharma, S., Lavoue, D., Cachier, H., Barrie, L. A., and Gong, S. L., Long-term trends of the black carbon concentrations in the Canadian Arctic, J. Geophys. Res., 109, D15203, doi:10.1029/2003JD004331, 2004.

US Environmental Protection Agency, Wood Heater Regulations, available at: http://www.epa.gov/oecaerth/monitoring/programs/ caa/whregs.html. (last access: May 2011), 2009.

Weitkamp, E. A., Sage, A. M., Pierce, J. R., Donahue, N. M., and Robinson, A. M.: Organic aerosol formation from photochemical oxidation of diesel exhaust in a smog chamber, Environ. Sci Technol., 41, 6969-6975, 2007.

Watson, J. G., Chow, J. C., and Chen, L.-W. A.: Summary of organic and elemental carbon/black carbon analysis methods and intercomparisons, Aerosol Air Qual. Res., 5, 65-102, 2005.

Yanowitz, J., McCormick, R. L., and Graboski, M. S.: In-use emissions from heavy-duty diesel vehicles, Environ. Sci. Technol., 34, 729-740, 2000. 